\title{
Faktor-faktor yang Berhubungan dengan Kejadian Preeklampsia pada Ibu Bersalin di Ruangan Camar II RSUD Arifin Achmad Provinsi Riau Tahun 2014
}

\section{Factors Associated with Incidence of Maternal Preeclampsia in Camar II ward Arifin Achmad Hospital in Riau Province Year 2014}

\section{Novita Lusiana}

\section{Program Studi DIII Kebidanan STIKes Hang Tuah Pekanbaru}

\begin{abstract}
ABSTRAK
Preeklampsia adalah sekumpulan gejala yang timbul pada wanita hamil, bersalin dan nifas yang terdiri dari hipertensi, edema dan proteinuria yang muncul pada kehamilan 20 minggu sampai akhir minggu pertama setelah persalinan. Masalah penelitian ini adalah faktor - faktor yang berhubungan dengan kejadian preeklampsia di Ruangan Camar II RSUD Arifin Achmad Tahun 2014. Penelitian ini bertujuan untuk mengetahui faktor penyebab terhadap kejadian preeklampsia di RSUD Arifin Achmad Provinsi Riau tahun 2014. Jenis penelitian ini adalah penelitian analitik kuantitatif, dengan desain penelitian yang digunakan adalah studi casse control. Populasi dalam penelitian ini adalah seluruh ibu bersalin di ruangan camar II yang tercatat di rekam medik ruangan camar II RSUD Arifin Achmad Provinsi Riau Tahun 2014 dengan jumlah populasi sebanyak 1247 persalinan. Analisis data yang dilakukan secara univariat dan bivariat menggunakan chi square. Dari hasil penelitian didapatkan bahwa tidak ada hubungan antara faktor umur dengan kejadian preeklampsia $(\mathrm{p}=0,114)$, tidak ada hubungan antara faktor paritas dengan kejadian preeklampsia $(\mathrm{p}=0,054)$, ada hubungan yang signifikan antara faktor keturunan dengan kejadian preeklampsia $(p=0,000)$, tidak ada hubungan antara faktor kehamilan kembar dengan kejadian preeklampsia $(p=$ $0,470)$, ada hubungan yang signifikan antara riwayat penyakit yang lalu dengan kejadian preeklampsia $(\mathrm{p}=0,000)$. Kesimpulan dari penelitian ini adalah ada hubungan yang signifikan antara faktor keturunan, riwayat penyakit yang lalu dengan kejadian Preeklampsia.
\end{abstract}

Kata Kunci: Faktor keturunan, Riwayat Penyakit yang lalu, Preeklampsia

\section{ABSTRACT}

Preeklampsia is a set of symptoms that occur in pregnant women, maternity and postpartum consisting of hypertension, edema and proteinuria that appeared at 20 weeks until the end of the first week after birth. Problem in this study are the factors associated with the incidence of preeclampsia in the room Camar II Arifin Achmad Hospital Riau Province Year 2014. This study aimeds to determine the causes of the incidence of preeclampsia in Arifin Achmad Province Riau Year 2014. This research method was quantitative analytica study, with case control design, retrospective study approach. The population in this study were all women giving birth in the room Camar II were recorded in the medical record room Camar II Arifin Achmad Hospital in Riau year 2014 with a total population of 1247 deliveries. Data analysis was performed using univariate and bivariate using with chi square. The result showed that there was no correlation between age and the incidence of preeclampsia $(p=0.114)$, there was no correlation between the parity with the incidence of preeclampsia $(p=0.054)$, there was a significant relationship between heredity with preeclampsia $(p=0.000)$, there was in no relationship between the factor twin pregnancies with preeclampsia $(p=0.470)$, there was a significant relationship between history of the disease and the incidence of preeclampsia $(p=0.000)$. Based on the result of this study concluded that there was no relationship between age, parity, twin pregnancy with preeclampsia, there is a significant relationship between heredity, history of the disease and the incidence of preeclampsia.

Keywords: Heredity, disease history ago, Preeclampsia

\section{PENDAHULUAN}

Preeklampsia adalah sekumpulan gejala yang timbul pada wanita hamil, bersalin dan nifas yang terdiri dari hipertensi, edema dan proteinuria yang muncul pada kehamilan 20 minggu sampai akhir minggu pertama setelah persalinan (Sudarti, 2014).

${ }^{1}$ Alamat Korespodensi: Novita Lusiana, Jl Singgalang VI Perum Yesti Garaha Blok D3, Email: novitalusiana.mkes@yahoo.com 
Menurut Survey Demografi Kesehatan Indonesia (SDKI) tahun 2012 menunjukkan bahwa penyebab langsung Angka Kematian Ibu (AKI) antara lain: perdarahan $42 \%$, eklampsia/preeklampsia 13\%, abortus $11 \%$, infeksi $10 \%$, partus lama/persalinan macet $9 \%$, dan penyebab lain 15\%.

Berdasarkan data awal yang diperoleh pada tanggal 24 Desember 2014 dari RSUD Arifin Achmad Provinsi Riau, pada tahun 2012 terdapat 210 kasus Preeklampsia (6,38\%) dari 3290 persalinan. Pada tahun 2013, terdapat 327 kasus (8,58\%) dari 3810 persalinan, pada tahun 2014 dari bulan Januari September terdapat 97 kasus $(7,77 \%)$ dari 1247 persalinan. Dilihat dari data diatas, kasus Preeklampsia pada tahun 2012 - 2013 mengalami peningkatan, sedangkan pada tahun 2014 mengalami penurunan. Oleh karena itu penulis ingin meneliti faktor-faktor yang berhubungan dengan kejadian preeklampsia di ruangan Camar II RSUD Arifin Achmad Provinsi Riau Tahun 2014.

\section{METODE}

Penelitian yang digunakan adalah penelitian analitik kuantitatif dengan jenis desain penelitian casse control. Kasus adalah ibu yang bersalin dengan preeklampsia yang tercatat di rekam medik camar II RSUD Arifin Achmad Provinsi Riau Tahun 2014 sebanyak 97 kasus yang ditemukan mulai dari bulan Januari - September 2014. Kontrol adalah ibu yang bersalin dengan tidak preeklampsia yang tercatat di rekam medik camar II RSUD Arifin Achmad Provinsi Riau Tahun 2014 sebanyak 97 kasus yang ditemukan mulai dari bulan Januari - September 2014. Analisis data pada penelitian ini dilakukan secara univariat dan bivariat menggunakan chi square.

\section{HASIL}

Hasil uji bivariat didapatkan variabel yang memiliki hubungan signifikan dengan kejadian preeklampsia yaitu faktor keturunan $(\mathrm{p}=0.000)$ dan faktor riwayat penyakit yang lalu $(\mathrm{p}=0.000)$, sedangkan faktor umur $(\mathrm{p}=0.114)$, faktor paritas $(\mathrm{p}=$ $0.054)$ dan faktor kehamilan kembar $(\mathrm{p}=0.470)$ tidak memiliki hubungan dengan kejadian preeklampsia. Ibu yang memiliki faktor keturunan lebih beresiko terhadap kejadian preeklampsia. Ibu yang mempunyai riwayat penyakit yang lalu (hipertensi kronik, diabetes, penyakit ginjal, dan obesitas) lebih beresiko terhadap kejadian preeklampsia (lihat tabel 1).

Tabel 1

Faktor-Faktor yang Berhubungan dengan Kejadian Preeklampsia

\begin{tabular}{|c|c|c|c|c|c|}
\hline \multirow[t]{2}{*}{ Faktor Penyebab Preeklampsia } & \multicolumn{2}{|c|}{ Kasus } & \multicolumn{2}{|c|}{ Kontrol } & \multirow{2}{*}{$\begin{array}{c}\text { P Value } \\
(95 \%)\end{array}$} \\
\hline & $\mathbf{N}$ & $\%$ & $\mathbf{n}$ & $\%$ & \\
\hline \multicolumn{6}{|l|}{ 1. $\quad$ Umur (th) } \\
\hline Beresiko $(<20$ dan $>35)$ & 51 & $26.3 \%$ & 40 & $20.6 \%$ & 0.114 \\
\hline Tidak Beresiko (20-35) & 46 & $23.7 \%$ & 57 & $29.4 \%$ & \\
\hline \multicolumn{6}{|l|}{ 2. $\quad$ Paritas } \\
\hline Beresiko (>3 anak) & 67 & $34.5 \%$ & 54 & $27.8 \%$ & 0.054 \\
\hline Tidak Beresiko (1-3 anak) & 30 & $15.5 \%$ & 43 & $22.2 \%$ & \\
\hline \multicolumn{6}{|l|}{ 3. Faktor Keturunan } \\
\hline Beresiko (Ada) & 16 & $8.2 \%$ & 40 & $20.6 \%$ & 0.000 \\
\hline Tidak Beresiko (Tidak Ada) & 81 & $41.8 \%$ & 57 & $29.4 \%$ & \\
\hline \multicolumn{6}{|l|}{ 4. Kehamilan Kembar } \\
\hline Beresiko (Ya) & 5 & $2.6 \%$ & 3 & $1.5 \%$ & 0.470 \\
\hline Tidak Beresiko (Tidak) & 92 & $47.4 \%$ & 94 & $48.5 \%$ & \\
\hline \multicolumn{6}{|l|}{ 5. Riwayat Penyakit Yang Lalu } \\
\hline Ada & 12 & $6.2 \%$ & 37 & $19.1 \%$ & 0.000 \\
\hline Tidak Ada & 85 & $43.8 \%$ & 60 & $30.9 \%$ & \\
\hline Total & 97 & $50.0 \%$ & 97 & $50.0 \%$ & \\
\hline
\end{tabular}




\section{PEMBAHASAN}

\section{Umur}

Ibu bersalin yang berumur 20-35 tahun lebih banyak dibandingkan ibu bersalin yang berumur $<20$ tahun atau $>35$ tahun beresiko mengalami preeklampsia. Biasanya terdapat pada wanita masa subur dengan umur ekstrim, yaitu pada remaja belasan tahun atau pada wanita yang berumur lebih dari 35 tahun. Hasil penelitian ini didukung oleh penelitian Wahyuni, dkk (2015) yang menyatakan bahwa tidak ada hubungan yang signifikan antara umur dengan kejadiaan preeklampsia pada Ibu Hamil di Rumah Sakit Roemani Muhammadiyah Semarang dengan nilai $\mathrm{p}$ value 0.768 .

Hasil penelitian ini juga di dukung oleh penelitian Fitriani (2009) yang menyatakan bahwa tidak ada hubungan yang bermakna antara umur dengan kejadian preeclampsia di Rumah Sakit Dr. Mohammad Hoesin Palembang, dengan nilai p.value $=$ $0,3>0,05$. dengan demikian berarti.

\section{Paritas}

Ibu yang memiliki paritas $>3$ beresiko mengalami preeklampsia dibandingkan ibu yang memiliki paritas 1-3. Menurut Winkjosastro (2005) pada multi paritas lingkungan endometrium disekitar tempat implantasi kurang sempurna dan tidak siap menerima hasil konsepsi, sehingga pemberian nutrisi dan oksigenisasi kepada hasil konsepsi kurang sempurna dan mengakibatkan pertumbuhan hasil konsepsi akan terganggu sehingga dapat menambah resiko terjadinya preeklampsia.

Hasil penelitian ini didukung oleh penelitian Wahyuni,dkk (2015) tentang "Faktor-faktor yang Berhubungan dengan Kejadian Preeklampsia pada Ibu Hamil di Rumah Sakit Roemani Muhammadiyah Semarang", yakni hasil uji statistik nilai p value 0.313 , berarti pada $\alpha=5 \%$ dapat disimpulkan tidak ada hubungan yang signifikan antara paritas dengan kejadiaan preeklampsia. Hasil penelitian ini juga didukung oleh penelitian Fauziah (2012) tentang "Hubungan Umur dan Paritas dengan Kejadian Preeklamsia Pada Kehamilan di Badan Layanan Umum Daerah Rumah Sakit Umum Daerah dr. Zainoel Abidin Banda Aceh", yakni hasil uji statistik nilai $\mathrm{p}=$ 0.778 ( $p>0.05)$, sehingga tidak ada hubungan antara paritas dengan kejadian preeklamsia pada ibu hamildi Badan Layanan Umum Daerah Rumah Sakit Umum Daerah dr. Zainoel Abidin Banda Aceh.

\section{Faktor Keturunan}

Ibu bersalin yang mempunyai faktor keturunan beresiko mengalami preeklampsia.
Menurut Sunarsih (2011) jika ada riwayatpreeklampsia/eklampsia pada ibu/nenek penderita, faktor resiko meningkat sampai $\pm 25 \%$. Bukti adanya pewarisan secara genetik paling mungkin disebabkan oleh turun resesif. Ada hubungan genetik yang telah ditegakkan, riwayat keluarga ibu atau saudara perempuan meningkatkan resiko terjadinya komplikasi hipertensi kehamilan dapat diturunkan pada anak perempuannya (Manuaba, 2007).

Hasil penelitian ini didukung oleh penelitian Rozikhan (2007) tentang "Faktor-faktor Risiko Terjadinya Preeklampsia Berat di Rumah Sakit Dr. H. Soewondo Kendal", yakni hasil uji statistic nilai $p$ value 0.001 , berarti pada $\alpha=5 \%$ dapat disimpulkan ada hubungan yang signifikan antara faktor keturunan dengan kejadiaan preeklampsia. Analisis risiko faktor keturunan didapatkan $\mathrm{OR}=7.110$, artinya ibu yang mempunyai faktor keturunan memiliki resiko 7 kali dibandingkan ibu yang tidak mempunyai faktor keturunan.

\section{Kehamilan kembar}

Ibu yang mengalami kehamilan kembar beresiko mengalami preeklampsia.

Menurut teori Winkjosastro (2008), preeklampsia lebih besar kemungkinan terjadi pada kehamilan kembar. Selain itu, hipertensi diperberat karena kehamilan banyak terjadi pada kehamilan kembar. Dilihat dari segi teori hiperplasentosis, kehamilan kembar mempunyai resiko untuk berkembangnya preeklampsia kejadian preeklampsia pada kehamilan kembar meningkat menjadi 4-5 kali dibandingkan kehamilan tunggal.

Hasil penelitian ini didukung oleh penelitian Wahyuni,dkk (2015) tentang "Faktor-faktor yang Berhubungan dengan Kejadian Preeklampsia pada Ibu Hamil di Rumah Sakit Roemani Muhammadiyah Semarang”, yakni hasil uji statistic nilai p value 1.00 , berarti pada $\alpha=5 \%$ dapat disimpulkan tidak ada hubungan yang signifikan antara kehamilan kembar dengan kejadiaan preeklampsia. Hasil penelitian ini juga didukung oleh penelitian Apri, dkk (2012) tentang "Faktor - Faktor yang Berhubungan Dengan Terjadinya Preeklampsia - Eklampsia di RSUD Raden Mattaher Jambi ", yakni hasil uji statistik nilai $\mathrm{p}=$ 0.612 ( $\mathrm{p}>0.05$ ), sehingga tidak ada hubungan antara kehamilan ganda dengan kejadian preeklamsia.

Riwayat penyakit yang lalu (hipertensi kronik, diabetes, penyakit ginjal, dan obesitas)

Ibu bersalin yang mempunyai riwayat penyakit yang lalu beresiko mengalami preeklampsia. 
Hal ini sesuai dengan teori yang dikemukakan Fadlun (2011), preeklampsia pada hipertensi kronik yaitu preeklampsia yang terjadi pada perempuan hamil yang telah menderita hipertensi sebelum hamil. Selain itu diabetes, penyakit ginjal, dan obesitas juga dapat menyebabkan preeklampsia. Kenaikan berat badan edema yang disebabkan oleh penimbunan air yang berlebihan dalam ruangan intertisial belum diketahui penyebabnya, mungkin karena retensi air dan garam.

Hasil penelitian yang didukung oleh penelitian Wahyuni,dkk (2015) tentang "Faktor-faktor yang Berhubungan dengan Kejadian Preeklampsia pada Ibu Hamil di Rumah Sakit Roemani Muhammadiyah Semarang", yakni hasil uji statistic nilai $\mathrm{p}$ value 0.01 , berarti pada $\alpha=5 \%$ dapat disimpulkan ada hubungan yang signifikan antara riwayat penyakit yang lalu dengan kejadiaan preeklampsia.

Hasil penelitian ini juga didukung oleh penelitian Apri, dkk (2012) tentang "Faktor - Faktor yang Berhubungan Dengan Terjadinya Preeklampsia Eklampsia di RSUD Raden Mattaher Jambi ”, yakni hasil uji statistik nilai $\mathrm{p}=0.000(\mathrm{p}<0.05)$, sehingga ada hubungan antara riwayat penyakit yang lalu dengan kejadian preeklamsia.

\section{KESIMPULAN}

Dari hasil analisis bivariat yang telah dilakukan, dapat disimpulkan bahwa terdapat hubungan signifikan antara faktor keturunan (genetik) dengan kejadian preeklampsia pada ibu bersalin di ruangan Camar II RSUD Arifin Achmad Provinsi Riau Tahun 2014 dengan nilai $\mathrm{p}=0,000(\mathrm{p}<0.05)$ dan terdapat hubungan yang signifikan antara faktor riwayat penyakit yang lalu dengan kejadian preeklampsia pada ibu bersalin di ruangan Camar II RSUD Arifin Achmad Provinsi Riau Tahun 2014 dengan nilai $\mathrm{p}=0,000(\mathrm{p}<0.05)$. Tidak terdapat hubungan antara faktor umur dengan kejadian preeklampsia pada ibu bersalin di ruangan Camar II RSUD Arifin Achmad Provinsi Riau Tahun 2014 dengan nilai $\mathrm{p}=0.114(\mathrm{p}>0.05)$. Tidak terdapat hubungan antara faktor paritas dengan kejadian preeklampsia pada ibu bersalin di ruangan Camar II RSUD Arifin Achmad Provinsi Riau Tahun 2014 dengan nilai $\mathrm{p}=0,054(\mathrm{p}>0.05)$. Tidak hubungan antara Faktor kehamilan kembar dengan kejadian preeklampsia pada ibu bersalin di ruangan Camar II RSUD Arifin Achmad Provinsi Riau Tahun 2014 dengan nilai $p=0,470(p>0.05)$.

\section{SARAN}

Bagi RSUD Arifin Achmad Provinsi Riau, diharapkan agar dapat melakukan anamnesa dengan tepat tentang faktor keturunan preeklampsia ibu dan menanyakan dengan benar tentang riwayat penyakit yang lalu yang pernah dialami oleh ibu. Bagi Ibu Bersalin, khususnya yang mempunyai faktor keturunan preeklampsia dan riwayat penyakit yang lalu seperti hipertensi kronik, diabetes, penyakit ginjal, dan obesitas diharapkan untuk dapat membatasi jumlah anak yang diinginkan dan melakukan pemeriksaan kehamilan sesering mungkin selama hamil, serta menjaga pola makan dengan gizi seimbang untuk mengatasi terjadinya kejadian preeklampsia saat persalinan.

\section{DAFTAR PUSTAKA}

Apri, dkk. 2012. Faktor - Faktor yang Berhubungan Dengan Terjadinya Preeklampsia-Eklampsia di RSUD Raden Mattaher Jambi. http://www.e(jurnal.com/2014/10/faktor-faktor-yangberhubungan-dengan-19.html? $\mathrm{m}=1$ diakses 18 Mei 2015).

Fauziah, 2012. Hubungan Umur dan Paritas dengan Kejadian Preeklampsia Pada Kehamilan di Badan Layanan Umum Daerah Rumah Sakit Umum Daerah dr.Zainoel Abidin Banda Aceh. Karya Tulis Ilmiah tidak diterbitkan. Program Studi DIII Kebidanan STIKes U'Badiyah, Banda Aceh.

Fauziyah,Y. 2013.Obstetri Patologi. Yogyakarta: Nuha Medika

Feryanto,F.A. 2011. Asuhan Kebidanan IV Patologi, Jakarta: Salemba Medika.

Fitriani, I. 2009. Hubungan Antara Umur dan Paritas Dengan Kejadian Preeklampsia Di Rumah Sakit Dr. Mohammad Hoesin Palembang. Database Jurnal Ilmiah Indonesia Vol. 1 No.2 .

Manuaba, Candradinata. 2007. Gawat Daruratan Obstetri Ginekologi Dan Obstetri Ginekologi Sosial Untuk Profesi Bidan. Jakarta : EGC.

2010. Gawat Daruratan Obstetri Ginekologi Dan Obstetri Ginekologi Sosial Untuk Profesi Bidan. Jakarta : EGC.

Mochtar, Rustam. 2007. Sinopsis Obstetri. Jakarta : EGC.

Notoatmodjo, S. 2005. Metodologi penelitian kesehatan. Yogyakarta : Rineka Cipta

2010. Metodologi Penelitian

Kesehatan. Jakarta: Rineka Cipta.

Register Ruang Bersalin RSUD Arifin Achmad Prov RIAU. Laporan Bulanan Ruang bersalin Camar II RSUD Arifin Achmad. Riau. .20122014. 
Rozikhan. 2007. Faktor-faktor Risiko Terjadinya Preeklampsia Berat di Rumah Sakit Dr. H. Soewondo Kendal.Semarang : Universitas Diponegoro.(http://eprints.undip.ac.id/18342/1 /ROZIKHAN.pdf.Diakses tanggal 28 April 2015).

Saifuddin, Dkk. 2009. Ilmu Kebidanan. Jakarta : Yayasan Bina Pustaka Sarwono Prawirohardjo.

Saryono, 2010. Metodologi Penelitian Kesehatan. Yogyakarta : Buku Kesehatan.

Sastrawinata, S. dkk. 2004. Obstetri Patologi Ilmu Kesehatan Reproduksi. Jakarta : EGC.

Sudarti, I.S. 2014. Patologi kehamilan, persalinan, nifas dan Neonatus Resiko Tinggi, Yogyakarta : Nuha Medika.
Sunarsih, Tri. 2011. Asuhan Kehamilan Untuk Kebidanan. Jakarta : Salemba Medika.

Wahyuni, dkk. 2015. Faktor-faktor yang Berhubungan dengan Kejadian Preeklampsia pada Ibu Hamil di Rumah Sakit Roemani Muhammadiyah Semarang. (http://jurnal.unimus.ac.id/index.php/jur bid/a eticle/view/1383 diakses tanggal 28 April 2015).

Winkjosastro, Dkk. 2008. Ilmu Kebidanan. Jakarta : Yayasan Bina Pustaka Sarwono Prawirohardjo. 